\title{
Typical Coronary Artery Disease Symptom
}

National Cancer Institute

\section{Source}

National Cancer Institute. Typical Coronary Artery Disease Symptom. NCI Thesaurus. Code C100024.

Deep, poorly localized chest or arm discomfort that is reproducibly associated with physical exertion or emotional stress and is relieved promptly (i.e., in less than 5 minutes) with rest and/or the use of sublingual nitroglycerin. Some patients may have no chest discomfort but present solely with jaw, neck, ear, arm, shoulder, back, or epigastric discomfort or with unexplained dyspnea without discomfort. If these symptoms have a clear relationship to exertion or stress or are relieved promptly with nitrates, they should be considered equivalent to ang ina. J Am Coll Cardiol, 2007; 50:1-157, doi:10.1016/j.jacc.2007.02.013 (Published online 6 August 2007). (ACC) 